\title{
ON THE DIRICHLET PROBLEM OF LANDAU-LIFSHITZ-MAXWELL EQUATIONS
}

\author{
JIAN ZHAI AND JIAYUN LIN
}

Abstract. We prove the existence and uniqueness of non-trivial stable solutions to LandauLifshitz-Maxwell equations with Dirichlet boundary condition for large anisotropies and small non-simply connected domains.

Mathematics subject classification (2010): 35B35, 35J65, 35K55, 35Q60.

Keywords and phrases: Landau-Lifshitz-Maxwell equations, Dirichlet boundary condition, demagnetizing field, steady state solutions, stability.

\section{REFERENCES}

[1] R. A. Adams, Sobolev spaces, Academic Press, 1975.

[2] F. Alouges AND K. BeAuchard, Magnetization switching on small ellipsoidal ferromagnetic samples, ESAIM Control Optim. Calc. Var., 15 (2009), 676-711.

[3] F. Alouges And A. Soyeur, On global weak solutions for Landau-Lifshitz equations: existence and nonuniqueness, Nonlinear Anal., 18, 11 (1992), 1071-1084.

[4] H. Amann, On the existence of positive solutions of nonlinear elliptic boundary value problems, Indiana Univ. Math. J., 21 (1971), 125-146.

[5] G. Anzellotti, S. BAldo And A. Visintin, Asymptotic behavior of the Landau-Lifshitz model of ferromagnetism, Appl. Math. Optim., 23 (1991), 171-192.

[6] J. M. BALL, A. TAHERI AND M. WINTER, Local minimizers in micromagnetics and related problems, Calc. Var. Partial Differential Equations, 14 (2002), 1-27.

[7] W. F. BRown, Micromagnetics, Wiley, New York, 1963.

[8] S. CAMPANATO, Generation of analytic semigroups by elliptic operators of second order in the Hölder spaces, Ann. Scuola Norm. Sup. Pisa Cl Sci., 4, 8 (1981), 495-512.

[9] G. CARbou And P. FABRIE, Time average in micromagnetism, J. Differential Equations, 147 (1998), 383-409.

[10] G. CARBOU AND P. FABRIE, Regular solutions for Landau-Lifshitz equations in a bounded domain, Differential Integral Equations, 14 (2001), 213-229.

[11] G. CARbou AND P. FABRIE, Regular solutions for Landau-Lifshitz equations in $\mathbb{R}^{3}$, Commun. Appl. Anal., 5, 1 (2001), 17-30.

[12] N-H. Chang, J. Shatah and K. Uhlenbeck, Schrödinger maps, Comm. Pure Appl. Math., 53 (2000), 590-602.

[13] A. DeSimone., R. Kohn, S. MÜLleR ANd F. OtTo, Recent analytical developments in micromagnetics, The Science of Hysteresis (Bertotti and Mayergoyz Eds.), 2, Academic Press, 2006, 269-381.

[14] A. Fardoun And A. Ratto, Harmonic maps with potential, Calc. Var. Partial Differential Equations, 5 (1997), 183-197.

[15] B. Guo AND F. Su, The global solution for Landau-Lifshitz, Maxwell equations, J. Partial Differential Equations, 14, (2001), 133-148.

[16] S. Gustafson AND J. Shatah, The stability of localized solutions of Landau-Lifshitz equations, Comm. Pure Appl. Math., 55, 9 (2002), 1136-1159.

[17] D. Gilbarg And N. TRudinger, Elliptic partial differential equations of second order, Springer, 1983. 
[18] F-B. HANG AND F-H. Lin, Static theory for planar ferromagnets and antiferromagnets, Acta Math. Sin. (Engl. Ser.), 17, 4 (2001), 541-580.

[19] A. HuberT AND R. SChäFER, Magnetic domains, Springer, 1998.

[20] R. D. JAmes AND D. KinderleHRer, Frustration in ferromagnetic materials, Contin. Mech. Thermodyn., 2, 3 (1990), 215-239.

[21] S. JIMBO, Y. MORITA AND J. ZHAI, Ginzburg-Landau equation and stable solutions in a nontrivial domain, Comm. Partial Differential Equations, 20, 11-12 (1995), 2093-2112.

[22] S. Jimbo AND J. ZHAI, Ginzburg-Landau equation with magnetic effect: non-simple-connected domains, J. Math. Soc. Japan, 50, 3 (1998), 663-684.

[23] S. Jimbo AND J. ZhaI, Domain perturbation method and local minimizers to Ginzburg-Landau functional with magnetic effect, Abstr. Appl. Anal., 5, 2 (2000), 101-112.

[24] S. Jimbo AND J. ZHAI, Instability in a geometric parabolic equation on convex domain, J. Differential Equations, 188, 2 (2003), 447-460.

[25] T. KATO, Perturbation theory for linear operators, Springer Verlag, 1966.

[26] R. V. Kohn And P. Sternberg, Local minimisers and singular perturbations, Proc. Roy. Soc. Edinburgh Sect. A, 111, 1-2 (1989), 69-84.

[27] A. LUNARDI, Analytic semigroups and optimal regularity in parabolic problems, Birkhäuser, 1995.

[28] L. D. LANDAU AND E. M. LifShitZ, On the theory of the dispersion of magnetic permeability in ferromagnetic bodies, Phys. Z. Sowjetunion, 8, (1935), Reproduced in Collected Papers of L.D. Landau, Pergamon, New York, 1965.

[29] O. A. LADYZHENSKAYA AND N. URAL' TSEVA, Linear and quasilinear elliptic equations, Academic Press, 1968.

[30] C. B. Morrey, Calculus of variations, Springer, 1966.

[31] Y. Meyer and R. Coifman, Wavelets, Cambridge, 1997.

[32] T. RIVIÉRE AND S. SERFATY, Compactness, kinetic formulation, and entropies for a problem related to micromagnetics, Comm. Partial Differential Equations, 28, 1-2 (2003), 249-269.

[33] M. SLODIČKA AND I. CIMRÁK, Numerical study of nonlinear ferromagnetic materials, Appl. Numer. Math., 46, 1 (2003), 95-111.

[34] A. Visintin, On Landau-Lifshitz equations for ferromagnetism, Japan J. Appl. Math., 2 (1885), 6984.

[35] J. ZHAI, Heat flow with tangent penalization converges to mean curvature motion, Proc. Roy. Soc. Edinburgh Sect. A, 128, 4 (1998), 875-894.

[36] J. ZHAI, Heat flow with tangent penalization, Nonlinear Anal., 28, 8 (1997), 1333-1346.

[37] J. ZHAI, Non-constant stable solutions in Landau-Lifshitz equation, Calc. Var. Partial Differential Equations, 7, 2 (1998), 159-171.

[38] J. ZHAI, Existence and behavior of solutions to the Landau-Lifshitz equation, SIAM J. Math. Anal., 30, 4 (1999), 833-847.

[39] J. ZHAI, Dynamics of domain walls in ferromagnets and weak ferromagnets, Physics Letters A, 234 (1997), 488-492.

[40] J. ZHAI, Theoretical velocity of domain wall motion in ferromagnets, Physics Letters A, 242 (1998), 266-270.

[41] J. ZHAI, Velocity of domain wall in ferromagnets with demagnetizing field, Physics Letters A, 279 (2001), 395-399.

[42] J. Zhai And J. FAng, Full velocity of micromagnetic domain walls, Physics Letters A, 318 (2003), $137-140$.

[43] J. Zhai, J. Fang And L. Li, Wave Map with Potential and Hypersurface Flow, Discrete Contin. Dyn. Syst., suppl. (2005), 940-946.

[44] J. Zhai AND L. Li, New results on Landau-Lifshitz ferromagnets model, Nonlinear Anal., 63, 5-7 (2005), e11-e21.

[45] J. ZHAI, Stable solutions to Landau-Lifshitz-Maxwell equations, Indiana Univ. Math. J., 54, 6 (2005), $1635-1660$. 